\title{
Chronic electrical stimulation reverses deafness-related depression of electrically evoked 2-deoxyglucose activity in the guinea pig inferior colliculus
}

\author{
Donald R. Schwartz a, Jochen Schacht ${ }^{a}$, Josef M. Miller ${ }^{\text {a }}$, Kirk Frey ${ }^{b}$ \\ and Richard A. Altschuler *,a \\ "Kresge Hearing Research Institute, Department of Otolaryngology and bepartments of Internal Medicine and Neurology, \\ University of Michigan, Ann Arbor, MI 48109, USA
}

(Received 2 December 1992; Revision received 3 July 1993; Accepted 7 July 1993)

\begin{abstract}
The $\left[{ }^{14} \mathrm{C}\right]$-2-deoxyglucose (2-DG) autoradiographic technique was used to study how auditory-related metabolic activity changes with deafness, and how chronic electrical stimulation of the deafened system may modify these changes. Guinea pigs were deafened by administration of kanamycin and ethacrynic acid. After nine weeks of deafness, the basal unstimulated uptake of 2-DG in the inferior colliculus (IC) was lower than in normal hearing control animals. $100 \mu \mathrm{A}$ of acute cochlear electrical stimulation significantly increased 2-DG uptake in normal hearing animals but did not evoke a significant increase in four or nine week deafened animals. Electrically elicited 2-DG uptake in the IC is therefore depressed by prolonged deafness. In a second series of experiments, after four weeks of deafness, animals were chronically electrically stimulated via a cochlear implant $2.5-3.5 \mathrm{~h}$ a day, five days a week for five weeks at $100 \mu \mathrm{A}$. Acute cochlear electrical stimulation following this chronic stimulation significantly increased 2-DG uptake in the contralateral IC over unstimulated levels. This suggests that some depressive effects of profound deafness on the auditory brain stem may he reduced or reversed with chronic electrical stimulation by a cochlear implant.
\end{abstract}

Autoradiographic technique; $\left[{ }^{14} \mathrm{C}\right]$-2-deoxyglucose; Metabolic activity; Deafness; Electrical stimulation; Auditory brainstem: Implant

\section{Introduction}

The question of the consequences of peripheral deafness on the mature central auditory system has taken on more importance with the development and increasing use of cochlear prostheses. We now know both from animal studies and from successful cochlear implants in patients, that cochlear prostheses are capable of activating the deafened central auditory pathways. Moreover, the possibility for activation persists after many years, even decades of deafness. However, implants demonstrate variable success often, in part, related to the prior duration of deafness (Clark 1987; Dowell et al., 1986; Gantz et al., 1988; Kileny et al., 1991). These observations are consistent with findings that auditory deprivation may cause many changes in the cytoarchitecture of the mature mammalian central auditory system, including shrinkage of cells and altered synapses (see reviews by Rubel et al., 1990; Miller et al., 1991). The present study was designed to determine if the effectiveness of electrical stimulation to activate the central auditory pathways decreases

\footnotetext{
* Corresponding author. Fax: (313) 764-0014.
}

with the duration of deafness and if so, whether chronic electrical stimulation of the deafened auditory system can reverse this trend. The $\left[{ }^{14} \mathrm{C}\right]-2$-deoxyglucose (2-DG) autoradiographic method (Sokoloff et al., 1977) was used to assess and compare metabolism in auditory brain stem nuclei generated by electrical stimulation with a cochlear implant.

\section{Methods}

\section{Subjects and protocol}

Pigmented guinea pigs (NIH outbred-strain, Murphy), 200-250 g, were randomly divided into four experimental groups: Group 1, normal hearing; group 2, four weeks deafened; group 3, nine weeks deafened; and group 4, nine weeks deafened, but chronically electrically stimulated during the last five weeks. All subjects were implanted with epidural electrodes for recording acoustic and electrical middle latency responses (A/E MLR) to assure the normal function of the auditory system of each subject, the effectiveness of the deafening procedure, and the appropriate operation of the cochlear prostheses following implantation prior to use. All surgical procedures were aseptic and 

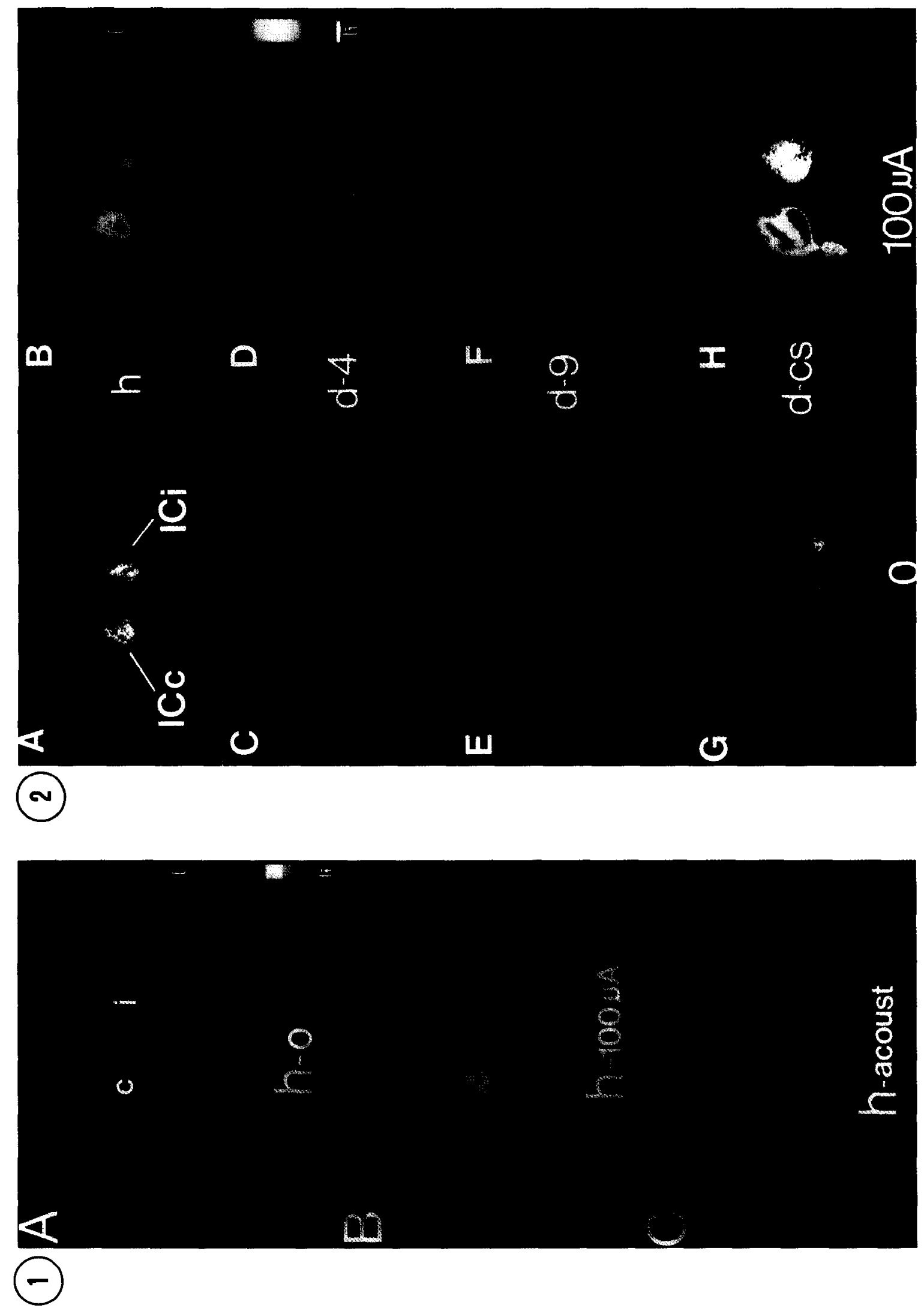
performed under ketamine $(40 \mathrm{mg} / \mathrm{kg}$ ) and xylazine $(10 \mathrm{mg} / \mathrm{kg})$ anesthesia.

Subjects from each group were administered 2-DG one hour prior to sacrifice. The auditory system of subgroups of subjects from each group were activated to varying degrees during the one hour 2-DG pulse. Group 1 (normal hearing): stimulus deprived (maintained in sound deadened chamber), stimulated with ambient lab sounds (approximately $50-60 \mathrm{~dB}$ ) or electrically stimulated at $100 \mu \mathrm{A}$ via a cochlear implant. Group 2: unstimulated or electrically stimulated at 100, 200 , or $300 \mu \mathrm{A}$. Groups 3 and 4: unstimulated or electrically stimulated at $100 \mu \mathrm{A}$. Three to five subjects per condition were used for each group.

All procedures of this study were reviewed and approved by the Unit of Laboratory Animal Medicine at the University of Michigan.

\section{Middle latency response recording}

MLR testing procedures have been described in detail elsewhere (Kraus et al., 1985; Burton et al., 1989; Jyung et al., 1989). Briefly, stainless steel screws were used as epidural recording electrodes. The reference electrode was placed along the midline $2 \mathrm{~cm}$ anterior to the bregma and two electrodes were placed $1 \mathrm{~cm}$ lateral to the bregma on the side contralateral to the implanted ear (active) and ipsilateral to the implanted ear (ground). At the time of the surgery all subjects were implanted with three additional epidural screws, equidistant surrounding the bregma, to which a head restraining screw was anchored with dental acrylic.

For acoustic stimulation a $10 \mathrm{~V}, 400 \mu$ s pulse at 5 pps was used to drive a Permaflex PDR 600 speaker. The click had an instantaneous maximum sound pressure level of $128 \mathrm{~dB}$ SPL, calibrated with a $1 / 4^{\prime \prime}$ Brücl and Kjaer microphone in a minimum volume coupler. Variously attenuated acoustic stimuli were delivered through a speculum tightly coupled into the external auditory canal of the right ear, uncompromised in animals with implanted left ears. For electrical stimulation, pulses from $25-1200 \mu \mathrm{A}(\mathrm{P}-\mathrm{P})$ at 5 pps were used. MLRs recorded from the active epidural elec- trode for $80 \mathrm{~ms}$ post stimulus epochs. The signal was amplified $(\times 10 \mathrm{~K})$ using a Grass P15 amplifier $(0.1-3 \mathrm{~K}$ band pass), averaged ( $N=256)$ and stored on an IBMAT computer. Software developed in house was used to generate averaged responses. Only animals with normal AMLRs were used in this investigation.

\section{Deafening}

Kanamycin $(400 \mathrm{mg} / \mathrm{kg}, \mathrm{SQ})$ was followed $2 \mathrm{~h}$ later by ethacrynic acid $(40 \mathrm{mg} / \mathrm{kg}$, IV) to produce deaf subjects (West et al., 1973, Jyung et al., 1989). AMLRs were used to assess the degree of deafness. Only animals with an AMLR threshold shift of $>80 \mathrm{~dB}$ SPL ('deaf animals') were used in this study.

\section{Electrical stimulation}

The inner ear was exposed via a defect in the mastoid bulla and a monopolar stimulating electrode was placed through the round window approximately 2 $\mathrm{mm}$ into the scala tympani. The ball-tipped $(250 \pm 25$ $\mu \mathrm{m}$ diameter) stimulating electrode (teflon-coated $90 \%$ platinum-10\% iridium 5T wire, Medwire Corp.) terminated in a percutaneous connector plug mounted to the skull with a screw and dental acrylic. A return electrode was placed along the bulla wall. The electrode leads along the exposed bone between the bulla defect and the percutaneous connector were stabilized with dental acrylic. Following surgery, chloramphenicol $(10 \mathrm{mg} / \mathrm{kg}, \mathrm{IM})$ and saline ( $3 \mathrm{ml} \mathrm{IP}$ and SQ) were administered. Electrodes were placed at least two weeks prior to 2-DG administration. Constant current, charge balanced, biphasic $(200 \mu \mathrm{sec} /$ phase $)$ square pulses were applied to the stimulating electrode at a rate of 100 pps for chronic stimulation and at 5 pps for the chronic stimulation of group 4 . Subjects were stimulated for $2.5-3.5 \mathrm{hrs} /$ day, 5 day/wk, to total 15 hrs/wk for MLR studies. The EMLR was observed immediately prior to the 2-DG pulse to assess proper electrode function. Unless otherwise stated, the current intensity used for cochlear stimulation was 100 $\mu \mathrm{A}$.

Fig. 1. Representative autoradiographs showing color-coded levels of 2-DG uptake in sections through the guinea pig inferior colliculus in hearing animals receiving either (A) no auditory stimulation (h-0), (B) unilateral electrical stimulation of the left cochlea at $100 \mu \mathrm{A}$ during the 2-DG pulse (h-100 $\mathrm{A}$ ), or (C) $78 \mathrm{~dB}$ unilateral acoustic stimulation of the left cochlea during the 2-DG pulse (h-acoust). $\mathrm{j}=$ inferior colliculus ipsilateral to the unilateral stimulations, $\mathrm{c}=$ inferior colliculus contralateral to the unilateral stimulations

Fig. 2. Representative autoradiographs showing color-coded levels of 2-DG uptake in sections through the guinea pig inferior colliculus. Sides are reversed so that left in the figures is contralateral to the stimulated ear. Animals in the left column $(A, C, E, G)$ received no stimulation (0), animals in the right column (B,D,F,H) received $100 \mu \mathrm{A}$ of electrical stimulation in the left ear during the 2-DG pulse (100 $\mu \mathrm{A})$. The first row $(A, B)$ were from hearing animals $(h)$, the second row $(C, D)$ were from animals deaf for four weeks $(d-4)$, the third row $(E, F)$ were from animals deaf for nine weeks $(\mathrm{d}-9)$ and the bottom row $(\mathrm{G}, \mathrm{H})$ were from animals deaf for four weeks which then received chronic electrical stimulation of the left cochlea via a cochlear implant for five weeks (d-cs). Electrical stimulation shows significant increases in 2-DG uptake in normal hearing animals and in chronically stimulated animals but not in deaf animals without chronic stimulation. ICc $=$ inferior colliculus contralateral to the side of stimulations, $\mathrm{ICi}=$ inferior colliculus ipsilateral to the side of stimulations. 


\section{2-DG Autoradiography}

[14C]-2-deoxyglucose (ARC Inc., St. Louis, MO) was evaporated (Savant Speed Vac Concentrator), reconstituted in physiologic saline and administered intramuscularly at $150 \mathrm{mCi} / \mathrm{kg}$ body weight. During the $2-\mathrm{DG}$ pulse (one hour) the animals remained unanesthetized, alert and restrained comfortably in the prone position in a dark, soundproof room. Subjects were then decapitated and the brain quickly harvested $(<8 \mathrm{~min})$ and frozen on a cryostat chuck with pulverized dry ice. Embedding matrix (Lipshaw) was painted on the brain which was stored at $-70^{\circ} \mathrm{C}$ while wrapped in parafilm and sealed in an air-tight bag. Serial frozen sections ( 20 $\mu \mathrm{m}$, transverse plane) were cut at a constant speed (Bright Instrument Co., model B2091) at $-17^{\circ} \mathrm{C}$. The sections were heat fixed $\left(60^{\circ} \mathrm{C}\right)$ to a standard microscope slide coated with gelatin and X-ray film (Kodak SB-5) was placed directly on the sections which were then fastened to metal $\mathrm{x}$-ray film cassettes (Spectronics Corp.). The sections and calibrated carbon-14 standards (ARC Inc.) were autoradiographed for five days. Autoradiograms were developed in a Kodak Xomat automatic processor.

Uptake of 2-DG in the auditory brain stem was determined by computerized image densitometry. The autoradiogram of an individual section was magnified, digitized and displayed on a monitor. Nuclei within the digitized image were identified and the relative optical density of minimally three digitized images of the anterior-posterior center within an auditory nucleus was sampled (central nucleus of the IC). The density measure was converted to $\mathrm{nCi} / \mathrm{g}$ by extrapolation from the linear interpolation relationship of the known values (in $\mathrm{nCi} / \mathrm{g}$ ) of the calibrated standards to their corresponding sampled optical density. The three samples were averaged. Normalized 2-DG uptake was calculated as the ratio of the average 2DG uptake of an auditory nucleus to an indifferent intrabrain control region. Following analysis of several putative control regions (including the cerebellar peduncle, cerebellum, vestibular nuclei and hippocampus), cerebellum gray matter, at the level of the dorsal cochlear nucleus was chosen as the indifferent intrabrain control region. The normalized mean 2-DG uptake data were analyzed using a two-tailed T-test with the confidence limit defined as $P \leqslant 0.05$.

\section{Results}

\section{2-DG uptake in normal hearing animals}

In normal hearing guinea pigs (group 1), quietly maintained in a sound proof booth, the levels of 2-DG uptake in IC were considerably above that observed in surrounding non-auditory structures, as has been previously described (Sokoloff et al., 1977; Ryan et al., 1982,

\section{HEARING}

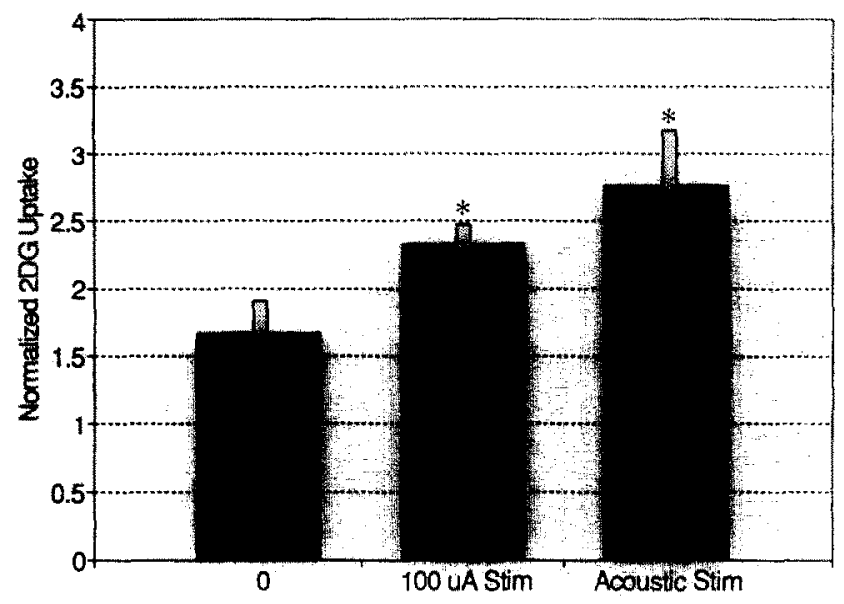

Fig. 3. A comparison of normalized 2.DG uptake in the right inferior colliculus in hearing animals with either no auditory stimulation $(0)$, unilateral electrical stimulation of $100 \mu \mathrm{A}$ in the left ear or bilateral ambient acoustic stimulation $(50-60 \mathrm{~dB})$. Uptake increases significantly with both electrical and acoustic stimulation. Bars show standard deviation. Asterisk indicates a significant difference from D4 0 .

1988; Webster et al., 1978). This is likely due to the considerable spontaneous activity of the auditory nerve. In the normal hearing animal, acoustic stimulation presented either unilaterally (78 dB SPL) (Fig. 1) or bilaterally at ambient sound levels (50-60 dB SPL) (Figs. 2 and 3) increased 2-DG uptake in the IC. This was a $67 \%$ increase in activity $(P<0.01)$ (Fig. 1). In normal hearing animals receiving $100 \mu \mathrm{A}$ of acute electrical stimulation by a cochlear implant, 2-DG levels in the contralateral IC were significantly $(P<0.004)$ increased by almost $40 \%$ over non-stimulated animals (Figs. 2 and 3 ), an increase that was not significantly different than the increase evoked by acoustic stimulation. An even greater increase, almost $75 \%$, was evoked at 200 and $350 \mu \mathrm{A}$. There was no significant difference in uptake evoked by 200 and $350 \mu \mathrm{A}$ stimulation, presumably reflecting saturation of the response. Such electrically evoked increases have been previously reported (Ryan et al., 1990) at intensities of 50-200 $\mu \mathrm{A}$.

\section{Effects of deafness on MLR}

The mean threshold shift of the AMLR following ototoxic drug treatment was more than $80 \mathrm{~dB}$ in all subjects used in these studies. The mean threshold of EMLRs for all was $27 \mu \mathrm{A}( \pm 13, N=46)$; and for the subjects chronically stimulated at $100 \mu \mathrm{A}$, threshold was $31 \mu \mathrm{A}( \pm 13, N=9)$. For this latter group thresholds ranged from $20 \mu \mathrm{A}$ to $50 \mu \mathrm{A}$. This chronic stimulation was provided at $6-14 \mathrm{~dB}$ above threshold for group 4. 


\section{Effects of deafness on 2-DG uptake}

Group 2 animals were examined four weeks after deafening with kanamycin and ethacrynic acid. In animals maintained quietly in a sound proof booth the resting level of 2-DG uptake in the IC was still greater than in surrounding non-auditory structures and was not significantly lower than in corresponding animals of group 1 (normal hearing) (Figs. 2 and 4). As opposed to the group 1 animals, however, in these animals $100 \mu \mathrm{A}$ of stimulation did not result in a significant increase in 2-DG uptake in the contralateral IC. A significant 2-DG uptake was however, seen at 200 or $350 \mu \mathrm{A}$ of stimulation (60\% increase, $P<0.007$ at 200 $\mu \mathrm{A})$. The absence of an evoked threshold increase in 2-DG uptake with $100 \mu \mathrm{A}$ of stimulation indicates that a threshold shift had taken place as a result of four weeks of deafness.

Group 3 results were comparable to group 2. The extra five weeks of deafness did not significantly change basal levels in IC nor the effects of $100 \mu \mathrm{A}$ of stimulation (Figs. 2 and 5). As in the group 2 animals, $100 \mu \mathrm{A}$ of stimulation did not yield a significant increase in contralateral IC 2-DG uptake over unstimulated levels.

\section{Effects of chronic stimulation}

In group 4 (nine weeks of deafness including five weeks of chronic stimulation), animals maintained quietly in a sound proof booth, the basal 2-DG levels in IC were comparable to group 1 normal hearing animals. As opposed to group 2 and 3 animals, in group 4

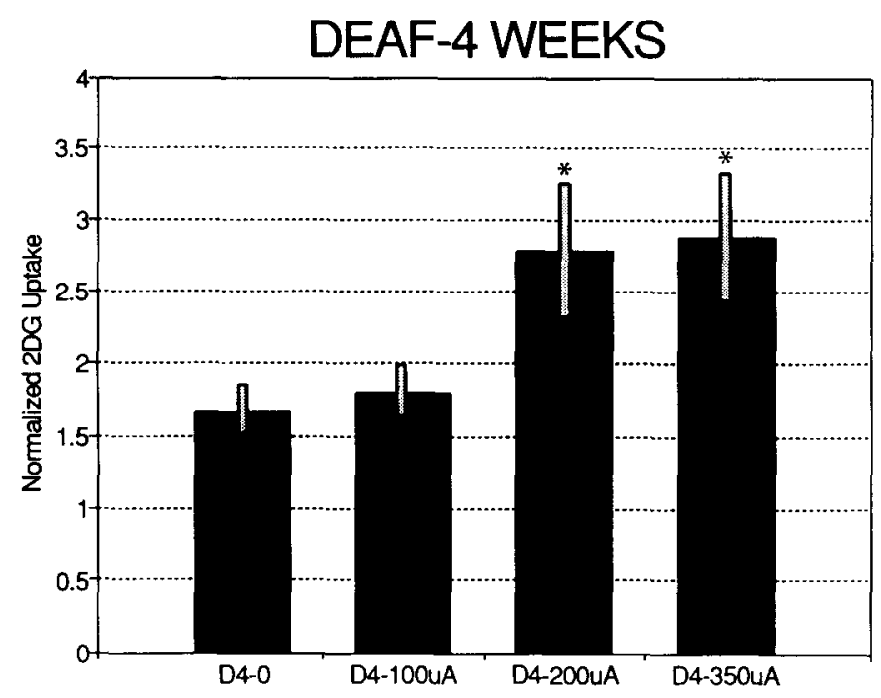

Fig. 4. A comparison of normalized 2-DG uptake in the right inferior colliculus animals after four weeks of deafness. Animals either received no stimulation (D4-0), or acute electrical stimulation of the left ear at 100, 250 or $350 \mu \mathrm{A}$ during the 2-DG pulse (D4-100 $\mu \mathrm{A}$, D4-200 $\mu \mathrm{A} \& \mathrm{D} 4-350 \mu \mathrm{A})$. No significant increase in 2-DG uptake was seen with $100 \mu \mathrm{A}$ of electrical stimulation, significantly increased uptake was not seen until $200 \mu \mathrm{A}$, a threshold shift from what was seen in normal hearing animals. Bars show standard deviation. Asterisk indicates a significant difference from D4-0.

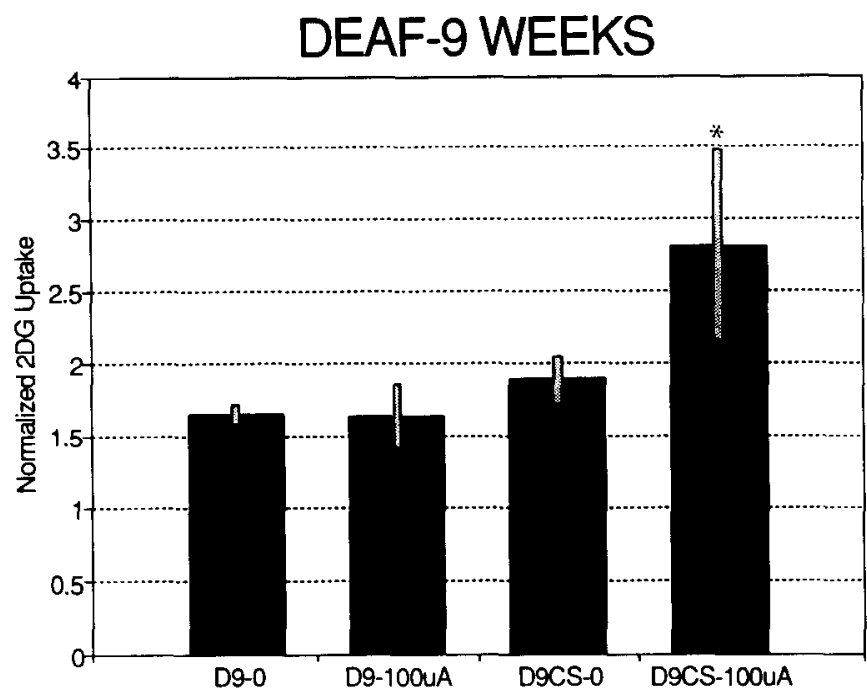

Fig. 5. A comparison of normalized 2-DG uptake in animals which were deaf for nine weeks, with one group receiving no stimulation until the time of the 2-DG pulse (D9-0, D9-100 $\mu \mathrm{A}$ ) and the other group receiving chronic stimulation (CS) in the left ear between weeks five and nine after deafening (D9CS- 0 , D9CS $100 \mu \mathrm{A}$ ). Animals received either no stimulation (D9-0. D9CS-0) or received acute electrical stimulation of the left ear at $100 \mu \mathrm{A}$ during the 2-DG pulse (D9-100 $\mu$ A, D9CS-100 $\mu$ A). Uptake of 2-DG was significantly increased in the group receiving chronic stimulation, and did not increase in the group without it. Bars show standard deviation. Asterisk indicates a significant difference from D4-0.

animals $100 \mu \mathrm{A}$ of stimulation significantly increased 2-DG uptake in the contralateral IC by almost $50 \%$ over non-stimulated levels $(P<0.004)$ (Figs. 2 and 5 ). The threshold shift seen in group 2 and 3 animals, therefore, was reversed by chronic stimulation in group 4 animals.

\section{Discussion}

The results of the present study indicate that the threshold for direct electrical cochlear activation of the central auditory system is increased following a four week or a nine week period of deafness. This deafness-related threshold shift is reversed by chronic stimulation between weeks four and nine. This suggests that some deafness-related changes in the auditory system may be reversed by chronic stimulation of the auditory nerve. While deafness-related changes of the auditory system are most marked when deafness occurs during embryonic development, this and other recent evidence indicates that significant changes also occur in mature animals. Deafness-related anatomical changes in mature mammals include loss of spiral ganglion cells (Webster and Webster, 1981; Jyung et al., 1989), shrinkage of neurons (Miller et al., 1991; Pasic and Rubel, 1990; Rubel et al., 1990; Webster, 1983) and alteration in synapses (Altschuler et al., 
1990, Gulley et al., 1978; Rees et al., 1985). These anatomical changes could affect both the basal activity and the evoked responsiveness of the auditory pathways. In fact, studies of electrically evoked ABRs and EMLRs studies show a depression in the amplitude input/output functions, which increases with the duration of deafness (Smith and Simmons, 1983; Jyung et al., 1989). Taken together, these data indicate that deafness appears to result in a decreased level of basal metabolic activity in auditory neurons, a decreased sensitivity of thcse cells to stimulation and a decreased responsiveness of cell populations within the auditory brain stem.

This study only reports on the contralateral IC, although other auditory brain stem regions were also examined ipsi- and contralaterally including ventral cochlear nucleus, dorsal cochlear nucleus, lateral superior olivary complex, medial nucleus of the trapezoid body, ventral nucleus of the lateral lemniscus and inferior colliculus. While the other regions (except for ipsilateral ventral and dorsal cochlear nuclei) all showed similar trends as results reported for contralateral IC, only the results in contralateral IC were statistically significant. It may be that there is greater plasticity in the IC than in other auditory brain stem regions.

Decreased ability to excite the deafened central auditory system may be a function of changes in the excitability of CNS cells as deafness-related degeneration of spiral ganglion cells progresses. Prosthetic stimulation of the auditory nerve appears to enhance the survival of spiral ganglion cells and central auditory structures in the absence of hair cells. Lousteau (1983) was the first to report that unilateral electrical stimulation in the bilaterally deafened animal (guinea pig) maintained higher densities of spiral ganglion cells in the stimulated ear. Several groups have subsequently demonstrated stimulation-enhanced maintenance of spiral ganglion cells (Hartshorn et al., 1991; Leake et al., 1991; Miller et al., 1991). We have also found in the mature guinea pig that much of the deafness-related flattening of the synapses of auditory nerve fibers on AVCN cells can be prevented with electrical stimulation (Altschuler et al., 1991; Miller et al., 1991). During development, electrical stimulation may also prevent or reduce deafness-induced shrinkage of cells in the cochlear nucleus of the mammal (Chouard et al., 1983; Hultcrantz et al., 1991; Matsushima et al., 1991) and the chick (Tucci et al., in press). In the mature mammal, however, while a deafness-related decrease in cochlear nucleus cell size has now been shown (Lesperance et al., 1992; Miller et al., 1991; Shannon Hartman and Wong, 1992) the reversal of these changes with electrical stimulation has yet to be demonstrated. For the most part these studies all indicate that if electrical stimulation is initiated at the beginning of deafness, at least some of the consequences of deafness on the CNS may be prevented or reduced. The current investigation is the first to indicate that some initial consequences of deafness may be reversed if electrical stimulation is initiated following a period of deafness. This concept has important implications for both clinical approaches to the application of the cochlear prosthesis in the profoundly deaf, as well as our basic understanding of the mechanisms which lead to depression or loss of CNS elements with deafness. If the processes initiated by deafening lead to degeneration, we would expect these changes to be irreversible. It appears, however, that the processes in the central auditory system that occur immediately following deafness are consistent with an initial 'down regulation' of cellular activity which can be reversed with electrical stimulation, as opposed to a true degeneration. It still remains to be determined how the duration of deafness influences the degree of reversibility, which will have important consequences in the treatment of deafness.

It is interesting that $100 \mu \mathrm{A}$ of electrical stimulation results in higher normalized 2-DG uptake in deafened animals with chronic stimulation than $100 \mu \mathrm{A}$ of electrical stimulation in normal hearing animals. This may be viewed in terms of recent studies showing chronic stimulation leads to an expansion of the cochleographic representation within the IC in the deafened animal (Snyder et al., 1990). It will be important in future studies to differentiate reversible and non-reversible down regulation and reorganization, and their implications for the return of function. It will also be necessary to define the novel characteristics of function that is 'returned' and apply this information to optimize the utility of cochlear implants for the deaf.

\section{Acknowledgements}

We would like to thank Dr. Hussam El-Kashlan for his invaluable assistance in image analysis of autoradiograms, Mrs. Kate Koorhan for her expert secretarial assistance, and Mr. Peter Finger and Ms. Joann Bonneau for helping produce graphs. These studies were supported by NIDCD Program Project Grant DC00274 , with partial funding of electrical suppression by the Lions Club of Michigan.

\section{References}

Altschuler, R.A., Horn, J.W., Plattner, E.A. and Miller, J.M. (1990) Prevention of deafness-related synaptic changes by cochlear prosthetic stimulation. Abstr. Soc. Neurosci. 16, 723.

Burton, M.J., Miller, J.M. and Kileny, P.R. (1989) Middle latency responses. I. Electrical and acoustic excitation. Arch. Otolaryngol. Head Neck Surg. 115, 59-62. 
Chouard, C.H.. Meyer, B., Josset, P. and Buche, J.F. (1983) The effect of the acoustic nerve chronic electric stimulation upon the guinea pig cochlear nucleus development. Acta Otolaryngol. 95, $639-645$.

Clark, G.M. (1987) The University of Melbourne-Nucleus multichannel implant. Adv. Otorhinolaryngol. 38, 1-189.

Dowell, R.C., Mecklenburg. D.J. and Clark, G.M. (1986) Speech recognition for 40 patients receiving multichannel cochlear implants. Arch. Otolaryngol. Head Neck Surg. 112, 1054-1059.

Gantz, B.J., Tyler, R.S., Knutson, J.F., Woodworth, G., Abbas, P., McCabe, B.F., Hinrichs, J.. Tye-Murray, N., Lansing, C.. Kuk, F. and Brown C. (1988) Evaluation of five different cochlear implant designs: audiological assessment and predictors of performance. Laryngoscope 98, 1100-1106.

Gulley, R., Wenthold, R.J. and Neises, G. (1978) Changes in the synapses of spiral ganglion cells in the rostral anteroventral cochlear nucleus of the waltzing guinea pig. Brain Res. 158, 279-294.

Hartshorn, D.O., Miller, J.M. and Altschuler, R.A. (1991) Protective effect of electrical stimulation on the deafened guinea pig cochlea. Am. Acad. Otolaryngol. Head Neck Surg. 104, 311-319.

Hultcrantz, M., Snyder, R., Rebscher, S. and Leake, P. (1991) Effects of neonatal deafening and chronic intracochlear electrical stimulation on the cochlear nucleus in cats. Hear. Res. 54, 272-280.

Jyung, R.W., Miller, J.M. and Cannon, S.C. (1989) Evaluation of eighth nerve integrity using the electrically evoked middle latency response. Am. Acad. Otolaryngol. 101. 670-682.

Kileny, P.R., Zimmerman-Phillips, S., Kemick, J.L. and Schmaltz. S.P. (1991) Effects of preoperative electrical stimulability and historical factors on performance with multichannel cochlear implant. Ann. Otol. Rhinol. Laryngol. 100, 563-568.

Kraus, N., Smith, D.I. and Grossman, J. (1985) Cortical mapping of the auditory middle latency response in the unanesthetized guinea pig. Electroencephalogr. Clin. Neurophysiol. 62, 219-26.

Leake, P.A., Hradek, G.T., Rebscher, S.J. and Snyder, R.L. (1991) Chronic intracochlear electrical stimulation induces selective survival of spiral ganglion neurons in neonatally deafened cats. Hear. Res. 54, 251-271.

I.esperance, M.M., Helfert, R.H. and Altschuler, R.A. (1992) Effect of deafness on cell size of neurons in guinea pig rostral AVCN. Abstr. Assoc. Res. Otolaryngol. 15, 76.

Lousteau, R.J. (1983) Increased spiral ganglion cell survival in electrically stimulated, deafened guinea pig cochleae. Laryngoscope 97, 837-842.

Matsushima, J-I., Shepherd, R.K., Seldon, H.L., Xu, S-A, and Clark, G.M. (1991) Electrical stimulation of auditory nerve in deaf kittens: Effects on cochlear nucleus morphology. Hear. Res. 56. $13.3-142$.

Miller, J.M., Altschuler, R.A., Niparko, J.K., Hartshorn, D.O., Helfert, R.H. and Moore, J.K. (1991) Deafness induced changes in the central nervous system: Reversibility and prevention. In:
A.L. Dancer, D. Henderson, R.J. Salvi, and R.P. Hamernik (Eds.), Noise Induced Hearing Loss. Mosby Year Book, St. Louis, pp. $130-145$.

Pasic, T.R. and Rubel, E.W. (1990) Rapid changes in cochlear nucleus cell size following blockade of auditory nerve electrical activity in gerbils. J. Comp. Neurol. 283, 474-80.

Rees, S., Guldner, F.H. and Aitkin, L. (1985) Activity dependent plasticity of postsynaptic density structure in the ventral cochlear nucleus of the rat. Brain Res. 325, 370-374.

Rubel, E.W.. Hyson, R.L. and Durham, D. (1990) Afferent regulation of neurons in brain stem auditory system. J. Neurobiol. 21, $169-96$.

Ryan, A.F., Woolf, N.K. and Sharp, F.R. (1982) Tonotopic organization of the central auditory pathway of the mongolian gerbil; a 2-deoxyglucose study. J. Comp. Neurol. 207, 369-280.

Ryan. A.F., Braverman, S., Woolf, N.K. and Axelsson, G.A. (1988) Auditory neural activity evoked by pure-tone stimulation as a function of intensity. Brain Res. 483, 293-2013.

Ryan, A.F., Miller, J.M., Wang, Z-X. and Woolf, N.K. (1990) Spatial distribution of neural activity evoked by electrical stimulation of the cochlea. Hear. Res. 50, 57-70).

Shannon-Hartman, S. and Wong, D. (1992) Electrical stimulation of cochleas in drug deafened guinea pigs: Neuroanatomical effects in cell types of the cochlear nucleus. Abst. Assoc. Res. Otolaryngol. 15,54 .

Smith, C. and Simmons, F.B. (1983) Estimating eighth nerve survival by electrical stimulation. Ann. Otol. Rhinol. Laryngol. 92, 19-23.

Snyder, R.L., Rebscher, S.J., Cao, K.. Leake. P.A. and Kelly, K. (1990) Chronic intracochlear stimulation in the neonatally deafened cat. I. Expansion of central representation. Hear. Res. 50 . $7-34$.

Sokoloff, L., Reivich, M., Kennedy, C., Des Rosiers, M.H., Patlak, C.S., Pettigrew, K.D., Sakurada. O. and Shinohara, M. (1977) The [14C]deoxyglucose method for the medsurement of local cerebral glucose utilization. J. Neurochem. 28, 897-916.

Tucci, D.L., Lambert, P.R., Spindel, J.H. and Ruth, R.A. (1993) Effect of auditory nerve electrical stimulation on morphology of cochlear nucleus neutons of the deafened chick. Hear. Res., in press.

Webster, W.R.. Serviere, J., Batini, C. and Laplante, S. (1978) Autoradiographic demonstration with 2-(14C)-deoxyglucose of frequency selectivity in the auditory system of cats under conditions of functional activity. Neurosci. Lett. 10,43-48.

Webster, M. and Webster, D.B. (1981) Spiral ganglion neuron loss following organ of Corti loss: A quantitative study. Brain Res. $212,17-30$.

Webster, D.B. (1983) Auditory neuronal size after unilateral conductive hearing loss. Exp. Neurol. 79, 130-140.

West, B.A., Brummet, R.E. and Hines. D.L. (1973) Interaction of kanamycin and ethacrynic acid. Arch. Otolaryngol. 98, 32-37. 